\title{
Isolamento e caracterização de bactérias hemolíticas de Acará Disco e Neon Arco-Íris
}

\author{
Isolation and characterization of hemolytic bacteria \\ Fish disc and Neon Rainbow
}

\author{
Adolfo Jatobá ${ }^{*}$; Bruno Correa Silva²; Felipe do Nascimento Vieira ${ }^{3}$; \\ José Luiz Pedreira Mouriño ${ }^{2}$; Walter Quadros Seiffert ${ }^{3}$
}

\section{Resumo}

O objetivo deste estudo foi isolar, identificar e determinar a capacidade hemolítica de possíveis bactérias patogênicas do Acará Disco (Symphysodon discus) e Neon Arco-íris (Melanotaenia praecox), e definir qual o antibiótico entre Trimetoprim, Florfenicol, Cloranfenicol, Norfloxacina, Eritromicina, Bacitracina, Enrofloxacina, Tetraciclina, Furazolidona e Clindamicina possui melhor efeito inibitório in vitro, e determinar a concentração inibitória mínima (MIC) para Cloranfenicol, Norfloxacina, Eritromicina e Enrofloxacina. Em um surto de mortalidade de peixes ornamentais foram isoladas nove cepas de bactérias Gram negativas, onde três hemolíticas foram identificadas, duas como Vibrio cholerae e uma como Citrobacter braakii. Com estas foram realizados antibiogramas e determinada a concentração inibitória mínima em duas diferentes temperaturas $\left(22\right.$ e $\left.30^{\circ} \mathrm{C}\right)$. Os antibióticos Enrofloxacina, Norfloxacina, Florfenicol, Cloranfenicol e Trimetoprim apresentaram os melhores resultados de inibição in vitro frente ao Vibrio cholerae e Citrobacter braakii. O MIC da Eritromicina e Enrofloxacina frente aos patógenos aumentou a $30^{\circ} \mathrm{C}$, enquanto que para o Florfenicol e a Norfloxacina o MIC não foi influenciado pela temperatura.

Palavras-chave: Symphysodon discus, Melanotaenia praecox, antibiograma, peixe ornamental, bacteriose, MIC

\begin{abstract}
The aim of this study was to isolate, identify and determine the ability of potential pathogenic bacteria hemolytic mite Disco (Symphysodon discus) and Neon Rainbow (Melanotaenia praecox), and define which of the antibiotic Trimethoprim, Florfenicol, Chloramphenicol, Norfloxacin, Erythromycin, Bacitracin, Enrofloxacin, Tetracycline, and Furazolidone Clindamycin has better inhibitory effect in vitro, and determine the minimum inhibitory concentration (MIC) for Chloramphenicol, Norfloxacin, Erythromycin and Enrofloxacin. In an outbreak of ornamental fish deaths were isolated nine strains of Gram negative, hemolytic where 3 were identified, two as Vibrio cholerae and one as Citrobacter braakii. With these strains were performed antibiogram and was determined the minimum inhibitory concentration at two different temperatures $\left(22\right.$ and $\left.30^{\circ} \mathrm{C}\right)$. Antibiotics Enrofloxacin, Norfloxacin, florfenicol, chloramphenicol and trimethoprim showed the best results in vitro inhibition against the Vibrio cholerae, and Citrobacter braakii. The MIC increased in $30^{\circ} \mathrm{C}$ for erythromycin and enrofloxacin against pathogens, while for Florfenicol and norfloxacin the MIC was not influenced by temperature.

Key words: Symphysodon discus, Melanotaenia praecox, antibiogram, ornamental fish, bacteriose, MIC

${ }^{1}$ Prof. do Instituto Federal Catarinense, IFC câmpus Araquari. E-mail: adolfo.jatoba@iff-araquari.edu.br

2 Pesquisadores do Laboratório de Camarões Marinhos, Universidade Federal de Santa Catarina, UFSC. E-mail: bcs85@hotmail. com; mourino@lcm.ufsc.br

${ }^{3}$ Profs. do Laboratório de Camarões Marinhos, Universidade Federal de Santa Catarina, UFSC. E-mail: felipe.vieira@ufsc.br; seiffert@cca.ufsc.br

* Autor para correspondência
\end{abstract}




\section{Introdução}

A indústria de peixes ornamentais está em expansão e suas comercializações ultrapassam 300 milhões de dólares. Diferentemente da piscicultura ornamental marinha que é baseada no extrativismo, mais de $90 \%$ dos peixes comercializados na piscicultura ornamental continental são cultivados, entre as mais cultivadas podemos destacar os gênero Symphysodon ssp. e Melanotaenia ssp. que apresentam uma grande variedade de colorações devido ao grande número de espécies e subespécies (KULLANDER, 1996; BROWN, 2003).

Existem diversas formas de se cultivar peixes, entretanto quanto mais intenso o cultivo maior a chance de ocorrer um desequilíbrio no sistema, facilitando a surgimento e disseminação de enfermidades, entre elas as bacterioses. Isto já foi observado em algumas espécies de peixes ornamentais como cavalo marinhos (Hippocampus reidi) e carpas coloridas (Cyprinus carpio koi) (MARTINS et al., 2010; ČÍŽEK et al., 2010) através do isolamento de bactérias patogênicas.

Durante uma bacteriose os antibióticos são a primeira alternativa para o tratamento, porém muitos produtores os utilizam de maneira inadequada resultando no aumento da resistência dos microorganismos presentes no ambiente aquático (ČÍŽZKEK et al., 2010), além de ser fonte de poluição ambiental. Por isto há necessidade de se determinar o melhor antibiótico e a sua concentração mais adequada para cada bactéria de acordo com o ambiente em que elas se encontram.

O objetivo deste estudo foi isolar, identificar e determinar a capacidade hemolítica de possíveis bactérias patogênicas do Acará Disco (Symphysodon discus) e Neon Arco-íris (Melanotaenia praecox), e definir qual o antibiótico dentre Trimetoprim, Florfenicol, Cloranfenicol, Norfloxacina, Eritromicina, Bacitracina, Enrofloxacina, Tetraciclina, Furazolidona e Clindamicina possui melhor efeito inibitório in vitro, e determinar a concentração inibitória mínima (MIC) para
Cloranfenicol, Norfloxacina, Eritromicina e Enrofloxacina, em duas diferentes temperaturas (22 e $30^{\circ} \mathrm{C}$ ).

\section{Material e Métodos}

Os peixes utilizados foram obtidos a partir de tanques de piscicultura com surtos de mortalidade, apresentando sinais clínicos como: perda da coloração, escurecimento da epiderme, hemorragias nas nadadeiras e natação errática.

Foram amostrados 20 acará discos e 10 neon arco-íris, anestesiados com benzocaína a $50 \mathrm{mg}$ $\mathrm{L}^{-1}$ e sacrificados. Fígado, rim e coração foram extirpados em condições de esterilidade para isolamento bacteriano. As amostras de tecidos foram maceradas em gral estéril com SSE (solução salina estéril) a $0,85 \%$ de $\mathrm{NaCl}$ na proporção de $1 \mathrm{~g}$ de amostra para $1 \mathrm{~mL}$. O macerado foi semeado em placas de Petri contendo Agar TCBS (Tiossulfato Citrato Bile Sacarose) e em AS (Agar Sangue), 5\% de sangue desfibrinado de carneiro, e incubadas por $48 \mathrm{~h}$ a $30^{\circ} \mathrm{C}$. Após os procedimentos de isolamento e purificação pelo método de esgotamento, as cepas foram mantidas em meio de cultura BHI (brainheart infusion broth).

Os usilados que apresentaram hemólise em AS e/ou cresceram em Agar TCBS, foram semeadas por esgotamento em TSA (triptone soya Agar) e incubadas por $24 \mathrm{~h}$ em estufa a $30^{\circ} \mathrm{C}$. Uma colônia foi retirada e suspensa em $5 \mathrm{~mL}$ de SSE $0,85 \%$ de $\mathrm{NaCl}$, e inoculada nas galerias do kit API 20E $\left(\right.$ Biomerieux $^{\circledR}$ ) para posterior identificação.

Após identificação foram realizados antibiogramas com Trimetoprim, Florfenicol, Cloranfenicol, Norfloxacina, Eritromicina, Bacitracina, Enrofloxacina, Tetraciclina, Furazolidona, Clindamicina.

O MIC adaptado de Miller et al. (2005) foi realizado em temperaturas de $22^{\circ} \mathrm{C}$ e $30^{\circ} \mathrm{C}$, em microplacas de 96 poços com fundo chato. Os antibióticos foram diluídos em meio de cultura $\mathrm{PB}$ 
(poorbroth)nasconcentrações iniciais de 500,0;50,0; 25,0; e 5,0 $\mu \mathrm{g} \cdot \mathrm{mL}^{-1}$ de Eritromicina, Enrofloxacina, Florfenicol e Norfloxacina, respectivamente. Estas concentrações foram determinadas a parti de ensaios prévios na concentração de $100,0 \mu \mathrm{g} \cdot \mathrm{mL}^{-1}$ para todos os antibióticos. Nas microplacas contendo $100 \mu \mathrm{L}$ de meio de cultura PB os antibióticos foram diluídos em serie em fator 1:2. As cepas hemolíticas foram inoculadas em $\mathrm{BHI}$ por $24 \mathrm{~h}$ a $30^{\circ} \mathrm{C}$, após este período diluídas 100 vezes serialmente (fator 10), em meio de cultura PB e $100 \mu \mathrm{L}$ foram inoculadas em cada poço da microplaca. Para controle negativo foram mensuradas as absorbâncias de $200 \mu \mathrm{L}$ de PB (para cada antibiótico); e para controle positivo $200 \mu \mathrm{L}(100 \mu \mathrm{L}$ de PB mais $100 \mu \mathrm{L}$ do inoculo bacteriano diluído, para cada bactéria). Todo o MIC foi realizado em triplicata.

As microplacas foram incubadas por $24 \mathrm{~h}$ a 22 e $30^{\circ} \mathrm{C}$. Após este período, foi mensurada a absorbância $(550 \mathrm{~nm})$ e $100 \mu \mathrm{L}$ de cada poço foi semeado em TSA para confirmar as inibições.

\section{Resultados e Discussão}

Foram isoladas, ao todo, 9 amostras de bactérias, sendo 4 de baço e 5 de fígado. Destas, oito apresentaram morfologia de bastonetes Gram negativos e uma de cocos Gram positivos, apenas uma cepa foi isolada do Neon arco-íris (Tabela 1). Das nove cepas isoladas, três apresentaram hemólise em AS e foram identificadas bioquimicamente, duas como Vibrio cholerae com 98,6 e 98,8\% (probabilidade de acordo com o fabricante) e uma como Citrobacter braakii com 99,8\%. A escolha de trabalhar com cepas hemolíticas foi justificada pela grande presença de hemorragias nos peixes extirpados para isolamento das bactérias. As demais foram criopreservadas para estudos posteriores.

Tabela 1. Diâmetros dos halos de inibição $(\mathrm{mm})$ dos antibióticos contra as cepas de bactérias isoladas de Acarás Disco e Neon Arco-Íris.

\begin{tabular}{|c|c|c|c|c|c|c|c|c|c|}
\hline Cepas & 1 & 2 & 3 & 4 & 5 & 6 & 7 & 8 & 9 \\
\hline $\begin{array}{c}\text { Órgão de } \\
\text { origem }\end{array}$ & Fígado $^{1}$ & Fígado $^{1 *}$ & Fígado & Fígado & Fígado & $\mathrm{BaçO}^{2}$ & Baço & Baço & Baço \\
\hline Antibiótico & \multicolumn{9}{|c|}{ Halo de inibição (mm) } \\
\hline Florfenicol & 31 & 34 & 38 & 20 & 32 & 25 & 23 & 32 & 29 \\
\hline Furazolidona & 14 & 19 & 14 & 20 & 17 & 20 & 11 & 14 & 9 \\
\hline Clindamicina & 17 & 13 & 11 & 0 & 0 & 0 & 11 & 12 & 12 \\
\hline Bacitracina & 0 & 0 & 0 & 0 & 14 & 0 & 0 & 0 & 9 \\
\hline Norfloxacina & 41 & 27 & 41 & 20 & 22 & 22 & 11 & 39 & 10 \\
\hline Trimetoprima & 35 & 28 & 12 & 36 & 26 & 24 & 14 & 14 & 0 \\
\hline Eritromicina & 19 & 21 & 0 & 0 & 18 & 14 & 20 & 0 & 20 \\
\hline Cloranfenicol & 24 & 24 & 45 & 24 & 45 & 19 & 24 & 20 & 23 \\
\hline Enrofloxacina & 39 & 35 & 39 & 38 & 46 & 28 & 18 & 31 & 20 \\
\hline Tetraciclina & 17 & 17 & 39 & 12 & 13 & 12 & 11 & 12 & 28 \\
\hline
\end{tabular}

Vibrio cholerae ${ }^{1}$; Citrobacter braakii ${ }^{2}$; ${ }^{*}$ Cepa isolada do Neon Arco-Íris

Fonte: Elaboração dos autores.

Os sinais clínicos observados nos peixes estão dentro dos descritos por Austin (2010) para peixes infectados com $V$. cholerae, esta bactéria está relacionado com diversas perdas na aquicultura, continental e marinha, acometendo peixes, camarões e moluscos. Este vibrio é característico por ser mais patogênico em temperaturas mais elevadas (21 $26^{\circ} \mathrm{C}$ ) e deixar de ser letal aos peixes a $16^{\circ} \mathrm{C}$. Outro fato importante é sua capacidade de ser patógeno para humanos, podendo ser caracterizado com uma zoonose (vide revisão AUSTIN, 2010). 
$\mathrm{Na}$ aquicultura o aparecimento de enfermidades bacterianas já foi observado em diversas espécies de peixes, incluindo os ornamentais como ciprinídeos e Kinguios (Carassius auratus) apresentando bacterioses oriundas Streptococcus iniae e Aeromonas salmonicida, em ambientes dulcícolas. No ambiente marinho podemos citar os cavalos marinhos (Hippocampus reidi ginsburg) que apresentaram surto de bacteriose oriundos do Vibrio alginolyticus (RUSSO; MITCHELL; YANONG, 2006; SHOTTS JUNIOR et al., 2006; MARTINS et al., 2010).

Diversos trabalhos mostram a importância do isolamento de micro-organismos a partir de animais aquáticos. Kent et al. (2009) sugerem a identificação dos patógenos como uma de suas recomendações contra enfermidades. Ao conhecer o agente patogênico podem-se definir estratégias de manejo e drogas a ser aplicado, caso necessário e viável.

O antibiograma é uma importante ferramenta para escolher o antibiótico mais adequado frente às bacterioses. Neste trabalho os antibióticos
Enrofloxacina, Norfloxacina, Florfenicol, Cloranfenicol e Trimetoprima demonstraram maior capacidade bactericida frente aos patógenos isolados, enquanto os antibióticos: Bacitracina, Clindamicina e Eritromicina apresentaram um baixo poder inibitório (Tabela 1). Este resultado de pode está relacionado com a exposição das cepas nas propriedades de onde os peixes foram enviados. Cepas como Enterococcus sp., V. harveyi, $V$. anguilarum e $V$. alginolyticus apresentaram resistência a oxitetraciclina e eritromicina, demonstrando que são boas indicadoras de resistencia microbiana (JATOBÁ et al., 2008).

Neste trabalho foi possível determinar o MIC dos antibióticos (Eritromicina, Enrofloxacina, Florfenicol e Norfloxacina) em ambas as temperaturas $\left(22\right.$ e $\left.30^{\circ} \mathrm{C}\right)$, exceto para o Florfenicol frente ao Vibrio cholera isolado do fígado do Neon arco-íris em que a maior dose testada $(12,500$ $\mu \mathrm{g} / \mathrm{mL}$ ) não foi capaz de inibi-lo (tabela 2). Entretanto observamos menores absorbâncias nas concentrações mais elevadas sugerindo que uma dose mais elevada de Florfenicol obtivesse sucesso na inibição do vibrio isolado do Neon arco-íris (cepa 2) (tabela 1).

Tabela 2. Concentração mínima inibitória $\left(\mu \mathrm{g} \cdot \mathrm{mL}^{-1}\right)$ dos antibióticos frente bactérias hemolíticas isoladas de Acarás Disco e Neon Arco-Íris Cepas isoladas do Acará disco ${ }^{1}$; cepa isolada do Neon arco-íris ${ }^{2}$

\begin{tabular}{ccccccc}
\hline Bactérias & \multicolumn{2}{c}{ Citrobacter braakii $^{1}$} & \multicolumn{2}{c}{ Vibrio cholerae $^{l}$} & \multicolumn{2}{c}{ Vibrio cholerae $^{2}$} \\
\hline Antibióticos & \multicolumn{9}{c}{ Temperatura } \\
\hline Enrofloxacina & $0.08-0.04$ & $0.16-0.08$ & $<0.04$ & $0.04-0.08$ & $<0.04$ & $0.31-0.16$ \\
Eritromicina & $15.63-7.81$ & $125.0-62.5$ & $15.63-$ & $125.0-62.5$ & $15.63-$ & $125.0-62.5$ \\
Florfenicol & $0.10-0.20$ & $0.10-0.20$ & $0.10-0.20$ & $0.10-0.20$ & $0.10-0.20$ & $>12.50$ \\
Norfloxacina & $<0.02$ & $<0.02$ & $0.02-0.04$ & $0.02-0.04$ & $0.02-0.04$ & $0.02-0.04$ \\
\hline
\end{tabular}

Fonte: Elaboração dos autores.

Os MIC's para Enrofloxacina frente às três bactérias hemolíticas isoladas (dois Vibrio cholera e uma Citrobacter braakii) estão dentro dos valores obtidos por Miller et al. (2005) para Aeromonas salmonicida (ATCC 33658), entretanto estes autores não constataram diferença entre as temperaturas de incubação, diferentemente do observado neste trabalho, em que Eritromicina necessitou dose cinco vezes maior e Enrofloxacina duas vezes superior a $30^{\circ} \mathrm{C}$ do que a $22^{\circ} \mathrm{C}$ para obter o efeito 
inibitório, enquanto para Norfloxacina e Florfenicol não observamos diferenças nas doses dos MIC's realizados nas diferentes temperaturas de incubação (tabela 2).

Em todos os poços semeados em TSA com valores da absorbância próxima ao controle negativo não foram observadas unidades formadoras de colônias, comprovando a inibição dos antibióticos nos MIC's.

A divergência nos resultados entre os antibióticos, influenciados ou não pelas diferentes temperaturas, pode estar relacionada com as diferentes vias de atuação de cada antibiótico, capacidade de crescimento de cada bactéria nas diferentes temperaturas avaliadas, assim como a interação destes fatores.

A resistência de bactérias isoladas de empreendimentos aquícolas já foi observada por Torkildsen et al. (2000) em Pecten maximus, carpas ornamentais Č́ížek et al. (2009), assim como em duas fazendas de salmão no Chile, onde as bactérias isoladas dos cultivos apresentaram o dobro de resistência a Florfenicol do que as amostras de referência, Escherichia coli (ATCC 25922) e Pseudomonas aeruginosa (ATCC 27853) (MIRANDA; ROJAS, 2007).

Para minimizar o desenvolvimento da resistência bacteriana, Wright (2005) sugeriu a utilização de antibióticos com diferentes vias de ação. Além disto, podemos ajustar as doses de acordo com temperatura do ambiente, antibiótico escolhido e patógeno presente no ambiente de cultivo. Assim como a utilização de probióticos (JATOBÁ et al., 2008) e vacinas de forma preventiva.

Com bases nos resultados apresentados concluise que a temperatura pode influenciar a efeito de um antibiótico e a patogenicidade das cepas isoladas deve ser confirmada através de uma infecção experimental e verificação dos mesmos sinais clínicos.

\section{Referências}

AUSTIN, B. Vibrios as causal agents of zoonoses. Veterinary Microbiology, Barcelona, v. 140, n. 3-4, p. 310-317, 2010.

BROWN, C. Habitat - predator association and avoidance in rainbowfish (Melanotaenia spp.). Ecology of Freshwater Fish, Norway, v. 12, n. 2, p. 118-126, 2003.

ČIZŽEK, A.; DOLEJSKÁ, M.; SOCHOROVÁ, R.; STRACHOTOVÁ, K.; PIAČKOVÁ, V.; VESELÝ, T. Antimicrobial resistance and its genetic determinants in aeromonads isolated in ornamental (koi) carp (Cyprinus carpio koi) and common carp (Cyprinus carpio). Veterinary Microbiology, Barcelona, v. 142, n. 3-4, p. 435-439, 2010.

JATOBÁ, A.; VIEIRA, F. N.; BUGLIONE, C.; SILVA, B. C.; MOURIÑO, J. L. P.; JERÔNIMO, G. T.; DOTTA, G.; MARTINS, M. L. Utilização de bactérias ácidolácticas isoladas do trato intestinal de tilápia-do-nilo como probiótico. Pesquisa Agropecuária Brasileira, Brasília, v. 43, n. 9, p. 1201-1207, 2008.

KENT, M. L.; FEIST, S. W.; HARPER, C.; HOOGSTRATEN-MILLER, S.; LAW, J. M.; SÁNCHEZ-MORGADO, J. M.; TANGUAY, J. L.; SANDERS, G. E.; SPITSBERGEN, J. M.; WHIPPS, C. M. Recommendations for control of pathogens and infectious diseases in fish research facilities. Comparative Biochemistry and Physiology, Vancouver, v. 149, n. 2, p. 240-248, 2009.

KULLANDER, S. O. Eine weitere übersicht der diskusfische, gattung symphysodon heckel. D. Aqua. Terr. Z. Sonderheft Diskus, Boca Raton, v. 1, n. 1, p. 1016, 1996.

MARTINS, M. L.; MOURIÑO, J. L. P.; FREZER, G.; SILVA, B. C.; JATOBÁ, A.; VIEIRA, F. N. Isolation and experimental infection of Vibrio alginolyticus in sea horse, Hippocampus reidi Ginsburg, 1933 (Osteichthyes: Syngnathidae) in Brazil. Brazilian Journal of Biology, São Carlos, v. 70, n. 1, p. 205-209, 2010.

MILLER, R.A.; WALKER, R. D.; CARSON, J.; COLES, M.; COYNE, R.; DALSGAARD, I.; GIESEKER, C.; HSU, H. M.; MATHERS, J. J.; PAPAPETROPOULOU, M.; PETTY, B.; TEITZEL, C.; REIMSCHUESSEL, R. Standardization of a broth microdilution susceptibility testing method to determine minimum inhibitory concentrations of aquatic bacteria. Disaeses of Aquatic Organisms, Germany, v. 64, p. 211-222, 2005. 
MIRANDA, C. D.; ROJAS, R. Occurrence of florfenicol resistance in bacteria associated with two Chilean salmon farms with different history of antibacterial usage. Aquaculture, Amsterdan, v. 266, n. 1-4, p. 39-46, 2007.

RUSSO, R.; MITCHELL, H.; YANONG, R. P. Characterization of Streptococcus iniae isolated from ornamental cyprinid fishes and development of challenge models. Aquaculture, Amsterdan, v. 256, n. 1-4, p. 105110, 2006.

SHOTTS JUNIOR, E. B.; TALKINGTON, P. D.; ELLIOTT, D. G.; MCCARTHY, D. H. Aetiology of an ulcerative disease in goldfish, Carassius auratus (L.): characterization of the causative agent. Journal of Fish Diseases, Ellis Horwood, UK, v. 3, n. 3, p. 181-186, 2006.

TORKILDSEN, L.; SAMUELSEN, O. B.; LUNESTAD, B. T.; BERGH, Ø. Minimum inhibitory concentrations of chloramphenicol, florfenicol, trimethoprimrsulfadiazine and flumequine in seawater of bacteria associated with scallops (Pecten maximus) larvae. Aquaculture, Amsterdan, v. 185, n. 2, p. 1-12, 2000.

WRIGHT, G. D. Bacterial resistance to antibiotics: enzymatic degradation and modification. Advanced Drug Delivery Reviews, Salt Lake City, v. 57, n. 10, p. 14511470, 2005. 